\title{
Classification, Design and Evaluation of Endoscope Robots
}

\author{
Kazuhiro Taniguchi ${ }^{1}$, Atsushi Nishikawa ${ }^{2}$, Mitsugu Sekimoto ${ }^{3}$, \\ Takeharu Kobayashi', Kouhei Kazuhara4, Takaharu Ichihara4, \\ Naoto Kurashita ${ }^{4}$, Shuji Takiguchi ${ }^{3}$, Yuichiro Doki $^{3}$, \\ Masaki Mori ${ }^{3}$, and Fumio Miyazaki ${ }^{2}$ \\ ${ }^{1}$ Graduate School of Engineering, The University of Tokyo, \\ ${ }^{2}$ Graduate School of Engineering Science, Osaka University, \\ ${ }^{3}$ Graduate School of Medicine, Osaka University, \\ ${ }^{4}$ Research \& Development Center, Daiken Medical Co., Ltd. \\ clopan
}

\section{Introduction}

With development of endoscopic surgery and medical robotics, surgery using endoscope robots has become a representative of robotic surgery. This chapter describes classification, design methods and evaluation methods of endoscope robots.

Expectations for a minimally invasive surgery have increased year by year with the dramatic advancement of image diagnosis technology, including CT and MRI. A camera (endoscope) and surgical instruments are inserted into tiny holes made in the patients' abdomen or chest region for surgical procedures. Compared to abdominal or open chest surgery, endoscopic surgery has less pain and has a greater advantage in cosmetic appearance as well as the economic advantages, resulting in its growing popularity. The most distinctive feature of endoscopic surgery is that the surgical field is observed through images taken by an endoscope, rather than the naked eye. The most important element to surgical safety and efficient operating is how well an endoscope reveals the field of view during surgery. Generally, a camera assistant operates the endoscope. The operation of the endoscope needs fine adjustment for the angle of the field of view and the distance of the surgical area as well as correct aiming of the endoscope at the surgical field. Camera assistants sometimes operate the endoscope according to instructions of a surgeon; however, camera assistants need to operate the endoscope using their judgment in understanding the surgeon's intentions so that they can move the endoscope according to how the surgery is progressing moment to moment. The operation of an endoscope by camera assistants requires as much proficiency as that of surgeons. There are not many surgeons who have sufficient proficiency in endoscopic surgery, which requires special techniques. In fact, it is not unusual for surgery to be interrupted due to a camera assistant not being sufficiently proficient in using the endoscope and is unable to obtain the exact field of surgery required. To solve this problem, "endoscope robots that can hold and position an endoscope instead of a human camera assistant" (Fig. 1) have been developed. Fig. 1(a) shows a usual endoscopic 
surgery where a human camera assistant operates an endoscope and Fig. 1(b) shows an endoscopic surgery using an endoscope robot. Among endoscope robots reported so far, Naviot $^{\text {TM }}$ (Kobayashi et al., 1999, Tanoue et al., 2006) made by Hitachi in Japan, AESOPTM (Sackier \& Wang, 1994) made by Computer Motion (Intuitive Surgical) in the U.S.A and EndoAssist ${ }^{\mathrm{TM}}$ (Finlay, 2001) made by Prosurgics in England have been commercialized and widely used. The commercialized endoscope robots operate according to surgeon's instructions with switches by hand or voice recognition technology. There are some robots, still being studied, which automatically position the endoscope while the robot itself interprets the surgeon movements. The endoscope positioning system (Nishikawa et al., 2006, Nishikawa et al., 2008)developed by Nishikawa et al. represents an automatic endoscope positioning robot.

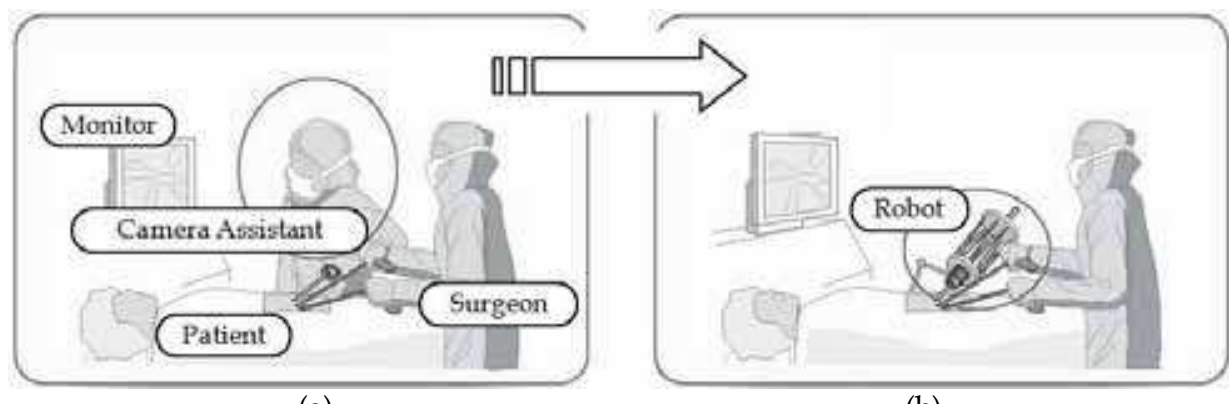

(a)

(b)

Fig. 1. Endoscopic surgery (a) A human camera assistant operates the endoscope. (b) An endoscope robot operates the endoscope.

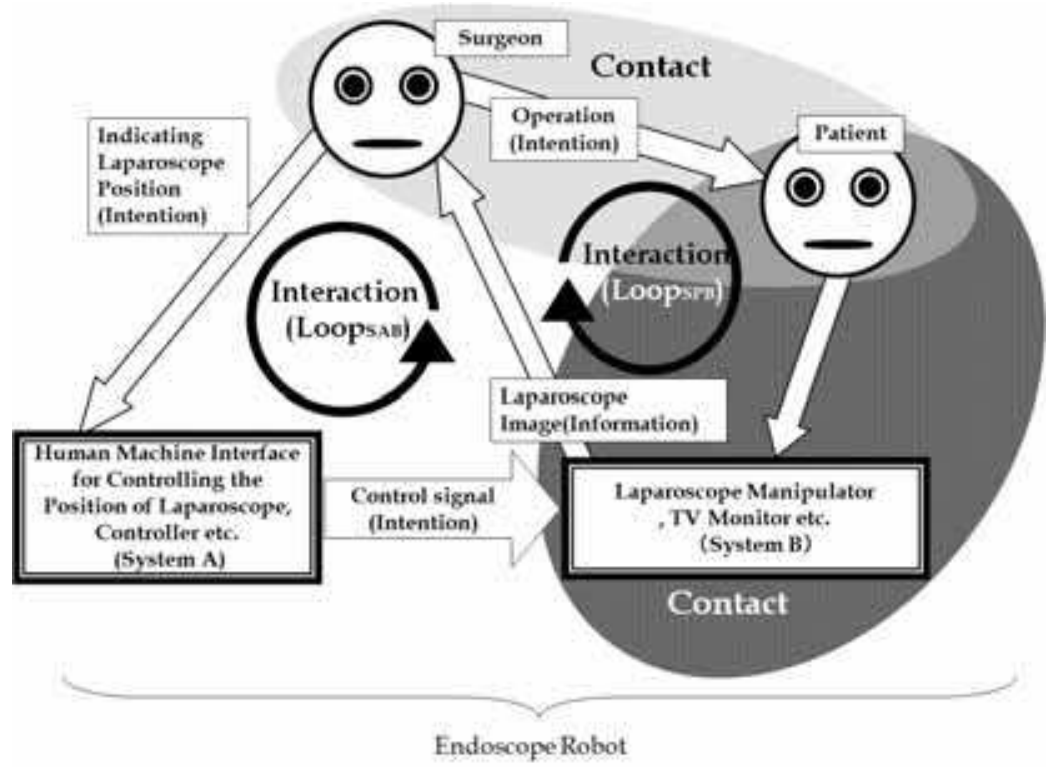

Fig. 2. Endoscope robot as an interactive media 
As shown in Fig. 2, we have developed endoscope robots by separating them into two systems: System A, which receives information (intention) from surgeons, and System B, which positions the endoscope and provides information, to the surgeons, including images taken by the endoscope. System A is the human interface and controller and System B is the manipulator, endoscope equipment and navigation equipment. Upon developing endoscope robots, we develop System A and System B separately and evaluate and review them separately. Then, System A and System B are integrated and evaluated comprehensively. When System A and System B are evaluated separately, a manipulator system where System B is simulated is used for System A and a human interface where System A is simulated is used for System B. More specifically, a robot with only necessary degrees of freedom is realized and commercially available endoscope equipment are used for System A and joystick interface is used for System B in most evaluations. In Fig. 2, a loop $\left(\right.$ Loop $_{\mathrm{SAB}}$ ) of "surgeon $\rightarrow$ System A $\rightarrow$ System B $\rightarrow$ surgeon" interaction is built between an endoscope robot and the surgeon. That is, an endoscope robot is treated as a part of the interactive media. In the endoscope robot, a surgeon works on System A (intention), System $A$ receives the intention from the surgeon and outputs a control signal (intention) to System B. As a result, System B is properly controlled and sends new information to the surgeon. Hence, surgeons can "expand their human abilities" through this interactive media. "Intention" means information to make an effect on items sent and received. We call mutual information flow between humans and the system which is performed to expand human abilities as an interaction loop. Proper information flow in the interaction loop establishes a strong link between humans and robots, resulting in cooperative work between humans and robots more efficient than that between humans and humans.

There is a loop (LoopsPB) of "surgeon $\rightarrow$ patient $\rightarrow$ System B $\rightarrow$ surgeon" in Fig. 2. This loop is an interaction loop between surgeons and patients through systems (System B) such as manipulators. Analysis of this interaction loop enables evaluation of surgery or robots.

This chapter focuses on Loop $\mathrm{SAB}$ for endoscope robot design methods and on Loop SPB $_{\text {for }}$ their evaluation methods.

\section{Classification of endoscope robots}

Table 1 and Fig. 3 demonstrate classification results of the following 27 kinds of endoscope robots which are commercialized or published in article for referee reading as of September 2009: a) A460 CRS Plus (Hurteau et al., 1994), b)AESOPTM (Sackier \& Wang, 1994), c)LARS(Taylor et al., 1995), d)EndoAssistTM (Endosista) (Finlay, 2001), e)Staubli Rx60(Munoz et al., 2000), f)ERM(Munoz et al., 2005), g)LapMan(Polet \& Donnez, 2004), h)RES(Mizhuno, 1995), i)Naviot ${ }^{\mathrm{TM}}$ (Kobayashi et al., 1999, Tanoue et al., 2006), j)PASEO(Nishikawa et al., 2003), k)HISAR(Funda et al., 1995), 1)ViKY(LER)(EndoControl, 2009, Long et al., 2007), m)5-DOFs Laparoscopic Assistant Robot(KaLAR) (Lee et al., 2003), n)FIPS(Buess et al.,2000), o)Imag Trac(Kimura et al., 2000), p)Wide-Angle View Endoscope(Kobayashi et al., 2004), q)Dual-View Endoscopic System(Yamauchi et al., 2002), r)Automatic Tracking And Zooming System(Nakaguchi et al., 2005), s)COVER(Taniguchi et al., 2006), t)P-arm(Sekimoto et al., 2009), u)Free hand(Prosurgics, 2009), v) Robolens (Sarkaret al., 2009), w)Swarup Robotic Arm (SWARM) (Deshpande, 2004), x)MST Laparoscope Manipulator(Szold et al., 2008, NGT, 2009), y)ROBOX(Rininsland, 1999, KIT, 2009, FZK, 2009), z) FELIX (Rininsland, 1999, FZK, 2009), aa) Paramis (Graur et al., 2009). 
Endoscope robots are treated as interactive media described in the previous section and separated by Loop SAB $_{\mathrm{B}}$ and Loop $\mathrm{SPB}_{\mathrm{SP}}$. For Loop $\mathrm{SAB}_{\mathrm{SA}}$, a human machine interface was examined for System A and a manipulator was examined for System B. Table 1 demonstrates the results of the human machine interface and Fig. 3 indicates the manipulator.

\begin{tabular}{|c|c|c|}
\hline & Loop $\mathrm{SAB}$ & \multirow[t]{2}{*}{ Loop SPB } \\
\hline & System A & \\
\hline a) A460CRS Plus & Remote hand switch & Human \\
\hline b) AESOPTM & $\begin{array}{l}\text { Voice recognition, remote hand switch, } \\
\text { foot pedal }\end{array}$ & Product \\
\hline c) LARS & Tool mounted switch & Animal \\
\hline $\begin{array}{l}\text { d) EndoAssist } \\
\text { (Endosista) }\end{array}$ & Head control & Human \\
\hline e) Staubli Rx60 & Voice recognition & Animal \\
\hline f) ERM & Voice recognition & Human \\
\hline g) LapMan & Tool mounted switch & Product \\
\hline h) RES & $\begin{array}{l}\text { Head control, equipment tracking, hand } \\
\text { and foot switches }\end{array}$ & Model \\
\hline i) Naviot ${ }^{\mathrm{TM}}$ & Tool mounted switch, head pose & Product \\
\hline j) PASEO & Face gesture & Animal \\
\hline k) HISAR & Tool mounted switch & Model \\
\hline 1) ViKY(LER) & voice recognition, foot control & Human \\
\hline $\begin{array}{l}\text { m)5-DOFs Laparoscopic } \\
\text { Assistant Robot(KaLAR) }\end{array}$ & Voice, equipment tracking & Animal \\
\hline n) FIPS endoarm & Tool mounted switch, voice recognition & Model \\
\hline o) I magTrac & Tool mounted switch, voice recognition & Human \\
\hline $\begin{array}{l}\text { p) Wide-Angle View } \\
\text { Endoscope }\end{array}$ & Remote hand switch & Animal \\
\hline $\begin{array}{l}\text { q) Dual-View } \\
\text { Endoscopic System }\end{array}$ & Remote hand switch & Animal \\
\hline $\begin{array}{l}\text { r) Automatic Traking } \\
\text { And Zooming System }\end{array}$ & Automatic tracking & Animal \\
\hline s) COVER & Face gesture & Animal \\
\hline t) P-arm & $\begin{array}{l}\text { Joystick, automatic operation, } \\
\text { touch screen, voice recognition }\end{array}$ & Animal \\
\hline u) FreeHand & Head pose & Product \\
\hline v) Robolens & Voice recognition & Human \\
\hline $\begin{array}{l}\text { w) Swarup Robotic Arm } \\
\text { (SWARM) }\end{array}$ & Remote controller & Human \\
\hline $\begin{array}{l}\text { x) MST Laparoscope } \\
\text { Manipulator }\end{array}$ & Equipment tracking & Animal \\
\hline y) $\mathrm{ROBOX}$ & $\begin{array}{l}\text { Voice recognition, mouse, foot pedal, } \\
\text { Equipment tracking }\end{array}$ & Human \\
\hline z) FELIX & Voice recognition & Model \\
\hline aa) Paramis & Voice recognition & Model \\
\hline
\end{tabular}

Table 1. Classification results of endoscope robots and human machine interface 


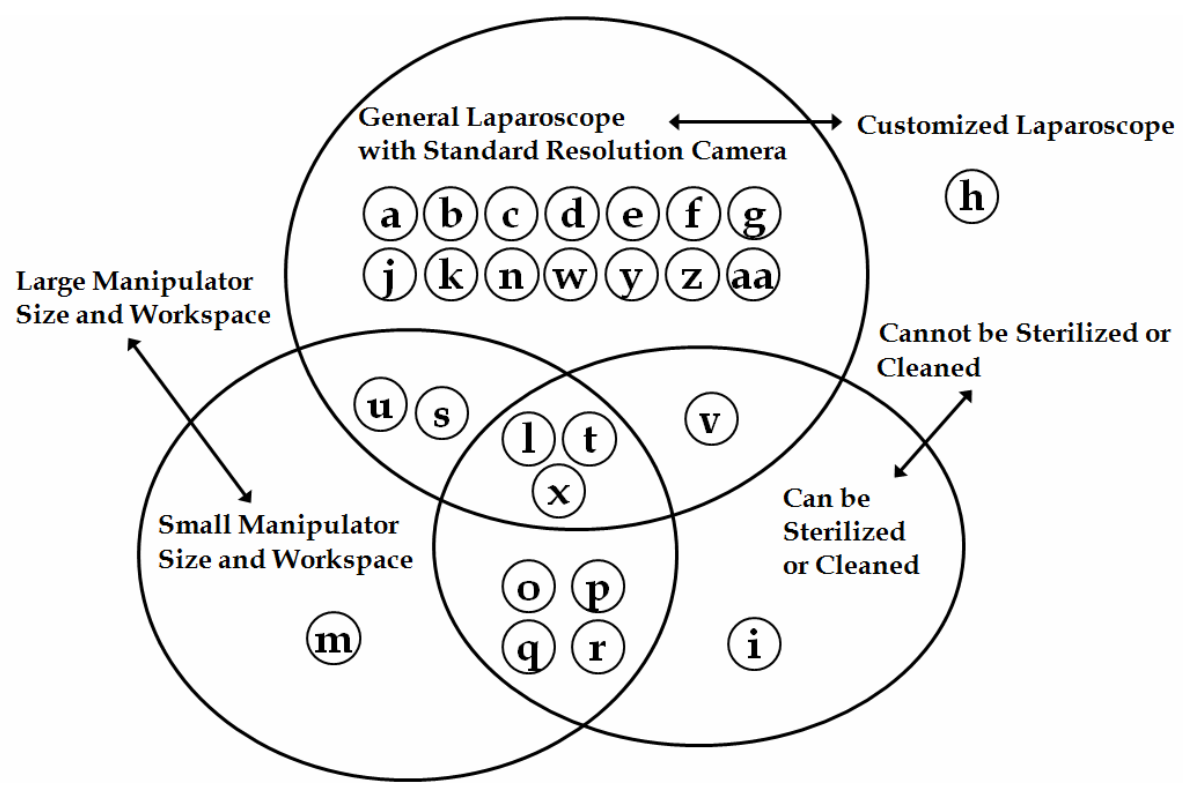

Fig. 3. Classification results of characteristics of endoscope robots and manipulation: A)A460 CRS Plus, b)AESOP, c)LARS, d)EndoAssist(Endosista), e)Staubli Rx60, f)ERM, g)LapMan, h)RES, i)Naviot, j)PASEO, k)HISAR, l) ViKY(LER),m)5-DOFs Laparoscopic Assistant Robot(KaLAR), n)FIPS, o)Imag Trac, p)Wide-Angle View Endoscope , q)DualView Endoscopic System, r) Automatic Tracking And Zooming System, s)COVER, t)P-arm, u)FreeHand, v) Robolens, w)Swarup Robotic Arm (SWARM), x)MST Laparoscope Manipulator, y)ROBOX, z) FELIX , aa) Paramis

Among "safety", "compact and lightweight", "cleanliness" and "usability: popular general endoscopes can be used" which are required on the medical front, "safety" should be independently discussed as a necessary condition for a medical robot; therefore, System B of each endoscope robot is classified according to "compact and lightweight", "cleanliness" and "usability". The definition of "compact and lightweight" is that a manipulator is attached with a general-purpose endoscope holder or an endoscope and manipulator are combined. The definition of "cleanliness" is that the endoscope robot parts which are used in clean fields can be sterilized. Robots that maintain cleanliness using a sterilized drape is classified as unclean. The most popular general endoscopes are OLYMPUS and KARL STORZ, which are commercially available. Table 1 also shows the subject of endoscope robots of LoopsPB. We examined whether each endoscope robot has been commercialized, whether an endoscope robot is used in human surgery, whether an endoscope robot is used only on animals, whether an endoscope robot is used only in in-vitro experiment or whether an endoscope robot model has been completed and has not been evaluated. We described them as product, human being, animal and model respectively in the table. Fig. 3 shows that endoscope robots satisfying all items are l) ViKY(LER), $t$ )P-arm , and $x$ )MST Laparoscope Manipulator only. Endoscope robots satisfying two out of three items of "compact and lightweight", "cleanliness" and "usability" are o)Imag Trac, p)Wide-Angle View Endoscope, q)Dual- View Endoscopic System, r) Automatic Tracking And Zooming System, s)COVER, 
and $\mathrm{u}$ )FreeHand. A special endoscope for robots are used in o)Imag Trac, p)Wide-Angle View Endoscope, q)Dual-View Endoscopic System and high resolution CCD camera with a resolution of one million pixel (general pixel is four hundred thousand) is used in $\mathrm{r}$ ) Automatic Tracking And Zooming System.

\section{Design of endoscope robots and implementation examples}

This section describes specificity of endoscope robots and required items for endoscope robots based on specificity. Examples of endoscope robots developed based on the required items are desmonstrated. Design of endoscope robots is design of LoopsAB shown in Fig. 2. Information that surgeons output to System A feeds back to surgeons from System B in the form of image taken by the endoscope. A variety of useful systems have been developed for System A of an endoscope robot with remote control techniques, voice recognition, and image processing technology.In contrast, the development for System B has been slow due to the complication of the system with regard to specificity of purpose and the extensive contact it is required to have with patients on the medical front. This section explains System $\mathrm{B}$, especially manupulator design.

\subsection{Specificity of endoscope robots}

Industrial robots operate under environments where the robots are isolated from humans; however, endoscope robots support surgery coming in contact with patients while the robots and surgeons closely interact. Industrial robots perform work which has been planned in advance under a closed, unvaring environment; however, endoscope robots are used for surgery in the medical front with high entoropy, where mistakes or failures are unacceptable. In addition, even though the surgery methods may be the same, the surgery contents vary in each case since the patients having the surgery vary. Hence, required items for robots of industry and endoscope robots are entirely different. Robots for industry required "high power", "high speed" and "high accuracy". Endoscope robots requires "safety" and "cleaness" since the robots come into physically contact with humans.

Upon designing robots, which work with humans, such as endoscope robots, "robot physical ability" and "robot computational ability" are points for designing the robots. It is necessary to design robots which have enough physical and computational abilities (artificial intelligence) to work with humans. To design a robot which does the housework including cleaning, washing or cooking, very high physical ability and computational ability are necessary for the robot. Physical and computational abilities of endoscope robots can be limited since the robots work with surgeons who have high intelligence for special tasks under special environments. A study group of Nishikawa et al. described before, have given much attention to interaction between humans and robots and realized the automatic operation of endoscope robots (Nishikawa et al., 2006, Nishikawa et al., 2008). For automation, Nishikawa analyzed the relatonship between endoscope images and surgical instruments in actual surgeries, and invented simple computation algorithms for endoscope robots specialized for specific tasks, without attempting to create endoscope robots that could understand the flow of the surgery, context of procedures or reasons behind actions. This algorithm has been designed focusing on the expansion of the ability of surgeons, and has obtained high reliability with introducing the concept of "fluctuation" as a characteristics of living bodies. This can be a good example of information in an interacton loop being 
optimized between the surgeons and the endoscope robots. To design endoscope robots, it is important to consider the specificity of the endoscope robots and optimize Loop SAB $_{\text {B }}$ interaction.

\subsection{Required items for endoscope robots}

Necessary elements for the construction of endoscope robots are broken into "required items", "basic items" and "enhancement items". The required items are necessary conditions for the endoscope robots. The basic items are strongly influential in the basic concepts of endoscope robots, and enhancement items are items that provide additional functions to the endoscope robots.

\subsubsection{Required items}

The required items are degree of freedom necessary for endoscope operations and safety as a medical equipment. It cannot be called an endoscope robot unless required items are met. First of all, we will describe degree of freedom. As shown in Fig. 4, since an endoscope operation during surgery is performed with insertion / retraction of an endoscope, roll around the insertion direction, and pitch and yaw based on the insertion site, the necessary degree of freedom for endoscope robots are four degrees of freedom. Roll is used to correct the top and bottom of image for direct-viewing endoscope and to observe the back of the organs for a oblique-viewing endoscope. Roll is not always necessary in surgery which targets narrow operation fields such as laparoscopic cholecystectomy. Among robots developed for the purpose of compact and to be lightweight, robots (Taniguchi et al., 2006) with three degrees of freedom with pitch, yaw and inserting, excluding roll, have been developed under conditions where the surgery target positions are limited. Degree of freedom as well as safety are the most important items for design of System B.

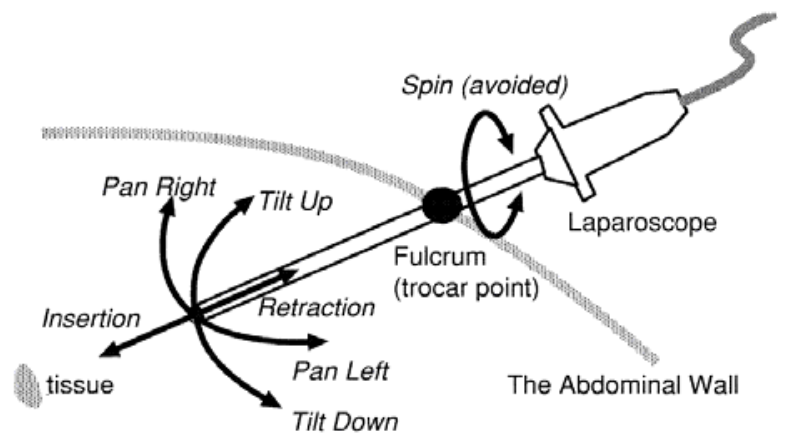

Fig. 4. Movement of endoscope: Since the endoscope is limited due to the insertion site, the endoscope has four degrees of freedom.

Next, we will describe safety. Suggestions on the safe use of medical robots include suggestions by Leveson et al (Leveson \& Turner, 1993) learn from "Therac-25 accidents" and suggestions (Taylor \& Stoianovici, 2003) by Taylor et al. Referring to the suggestions, we have the following points for securing safety when using endoscope robots.

- It is essential to secure mechanistic safety, and furthermore, the safety is secured by a control program (software) .

- Several completely independent safety devices are used. 
- While endoscope robots are being developed, documents are created and managed, and examinations are steadfastly performed and discussed with the results being thoroughly managed. The quality of the products is fastidiously managed.

- Several emergency cease functions are equipped. The emergency cease functions shall be installed at positions where the surgeons or nurses can immediately stop a endoscope robot.

- Considering the environment where medical staff will use the robots, clinicians, medical staff, medical device manufacturers and engineers, in coordination, assess the risks. Opinions from the related meetings are emphasized.

- The systems are designed so that surgeons can respond to stalled or runaway endoscope robots due to robot failure or dramatic environment changes, such as natural disasters, including earthquakes.

Mechanisms to secure the above safety are equipped with System A and System B separately and each relationship shall be clarified.

When study phases progress and practical use of endoscope robots is aimed at, it is necessary to comply with international standards including ISO and IEC on safety and JIS, Europe and U.S.A standards.

The methods to secure safety of endoscope robots which are being studied and developed are described below. AESOP, which were commercialized in the 90's and have been used worldwide, uses two control safety securing methods, "low limit setting" and "control disable function". The low limit setting is a function to secure safety, in which the lowest descendent position of a robot arm is set before surgery and the software controls the arm so it will not descend below the position crushing a patient's body during surgery. The control disable function stops the arm movement when the patient moves, stress is applied to the arm movement, or the magnet for installing the endoscope is dislocated when something hits the tip of the endoscope or shear stress is applied to the endoscope installation portion of the arm. AESOP is safety managed by a control program and mechanical safety is not secured. In addition, safety mechanism of System A and System B is not independent and we judge that safety is not sufficiently secured. Next, we will describe how to secure safety for Naviot ${ }^{\mathrm{TM}}$. As methods to secure mechanical safety, "optical zoom mechanism", "five joints link mechanism" and "limitation of degree of freedom" are introduced. In addition, the safety for System A and System B is completely independent. The optical zoom mechanism does not have a direct acting movement toward the interperitoneal direction by endoscopes and there is no possibility of interference with organs. The driving range of five link mechanisms is mechanically limited. Even when the endoscope robots malfunction or operate incorrectly, the robots do not move violently, the upper space of the abdominal cavity is secured and the surgery field is not interrupted. Limiting the degree of freedom and simplifying mechanisms cause less malfunction or incorrect movements. To secure control safety, a "status monitor function" is equipped. This function has function checkout functions before surgery and emergency cease functions when an overload (interference between patients or medical staff and robots) is observed during surgery. In addition, Naviot $^{\mathrm{TM}}$ has a measure against electric insulation and an emergency cease switch. With all things considered, it is very safe. Many endoscope robots have been studied and developed, some of which do not secure sufficient safety; only mechanical safety is secured by processing values of a pressure sensor with software, or, only a degree of freedom around the insertion site is mechanically realized, resulting in insufficient safety. 


\subsubsection{Basic items}

The basic items include the dimension of the endoscope robot, methods to secure cleanliness, installation methods and the kinds of endoscopes used. Determining these items lead to determine concepts of endoscope robots, especially in System B. Changing the basic items often leads to changing the basic structure of System B of an endoscope robot. Changing the basic items makes an endoscope robot totally different. First of all, the dimension of endoscope robots is described. In Japan, development of compact and lightweight robots is popular. Compact and lightweight endoscope robots have advantages, such as they can be easily installed, cleanliness can be easily secured or it does not interrupt the surgery. Next, installation area of endoscope robots is described. There are four areas to be installed, the floor near a surgical table in the operating room, hanging from the ceiling near the surgical table, on the surgical table or on the abdomen of the patient. In many studies, the endoscope robot is installed on the floor of the operating room or on the surgical table. Efficiency when an endoscope robot is installed on the abdomen of the patient has been studied recently. It is better to discuss installation positions and installation methods of an endoscope manipulator while considering that a surgical table height or slant is sometimes adjusted during surgery. Then, a method to secure cleanliness is described. There are two kinds of methods to secure cleanliness of the endoscope robots, one of which is to cover the endoscope robot with a sterilized drape and the other is to sterilize only the mechanism used in the clean fields.

A sterilized drape may tear during surgery due to the robot's movement. Covering the robot with a sterilized drape would be a big burden to medical staff. Finally, the kinds of endoscopes used are described. Either commercially available endoscopes or endoscopes developed for a specified endoscope robot are used. We think the former is preferable. Compared to the ones developed for endoscope robots, it is better to use economic and high image quality endoscopes appropriate for the medical front which has been developed by endoscope manufacturers, and apply them to the endoscope robots. This has the advantage when the endoscopes are comprehensively evaluated from a point of view of cleanliness, economic efficiency and securing stability of the field of view.

\subsubsection{Enhancement items}

Enhancement items include easy installation, re-installation and removal of endoscope robots, high availability (troubleproof), easy operation and easy installation and removal of endoscopes during surgery. Easy installation, re-installation and removal of endoscope robots mean easy preparation for surgery and clean up, leading to improved safety. When emergency situations such as the failure of an endoscope robot, occurs, it is preferable that the endoscope robot is rapidly removed from the operation field and the surgery can be switched to traditional abdominal surgery. Since it takes time to install large endoscope robots and which need sterilization drapes, the dimension of endoscope robots or methods to secure cleanliness influences the ease of installation, re-installation and removal of endoscope robots.

It is necessary to clean the lens at the tip of an endoscope several times during surgery because of blood, mists or tarnish. A function that the endoscope can be easily installed or removed to or from the robot is important to secure stable field of view. A human camera assistant can clean the lens of an endoscope for $20 \mathrm{sec}$. during surgery; therefore, the same performance is required for endoscope robots. 
Operability of endoscope robots depends on System A. To avoid malfunctions it is preferable that System A with which surgeons directly give instructions to the robots, can be viscerally operated and can operate endoscope robots freely without using major equipment. The key to optimize Loop $\mathrm{SAB}_{\mathrm{B}}$ is enhancement items of System A.

It is preferable that endoscope robots be designed considering affordance and the directions on how to use the endoscope, be quickly and easily understood. It is also preferable that special training or skills are not necessary to use endoscope robots and people using them for the first time can use them easily.

\subsubsection{Others}

The endoscope robots shall be designed so as not to be regarded as an alternative to the human camera assistant, but as an expansion of the surgeon's skill. The surgeons should be made to feel comfortable; reassuring them that they will always be in control of the robots. It is necessary that surgeons viscerally understand all movement of the robots.

Finally, it is understood that developing endoscope robots is not to imitate the hand movements of surgeons. The work done by surgeons follows the hand movement of humans; movement that is not suitable for robots. Upon developing endoscope robots, the goals shall be correctly specified, considering the optimized mechanism, or optimized system to obtain the goals and how to optimize each interaction group (Loop SAB $_{\text {and }}$ Loop $\left._{\mathrm{SPB}}\right)$.

\subsection{Implementation example of endoscope robot}

This section describes P-arm (disposable endoscope positioning robot) that we developed as an implementation example of endoscope robots.

\subsubsection{Basic concepts}

We mainly focus on "safety", "cleanliness" and "usability" and have defined the basic concept of endoscope robots as follows:

- The robots are equipped with a mechanism that if the endoscope robot, coming into contact with patients or doctors, applies a force that may cause harm, a structure that joins of the mechanism manipulator is dislocated and the force is mechanically released. Even if the joints of the manipulator are dislocated, the endoscope can be positioned (safety).

- Parts that operate in clean fields shall be disposable. Disposable parts enable "secure cleanliness" and "warranty of quality of endoscope robots". Since maintenance is unnecessary, inconvenience to the medical front can be reduced (cleanliness) (quality: safety).

- Endoscope robots shall be compact and lightweight. Endoscope robots shall weight less than the endoscopes (usability).

- Endoscope robots are mounted on the surgical table. A mechanism which can freely change endoscope robots' position and posture on a surgical table according to surgical targets is equipped (usability).

- Generally commercially available endoscopes (direct-view endoscope and obliqueviewing endoscope) can be operated (usability).

The critical matter of having endoscope robots that can be disposable is dependent upon the economic efficiency of the endoscope robots. Disposable endoscope robots require that they 
can be manufactured at a competitive cost. As a method to realize endoscope robots manufacture at a competitive cost, we decided that "the interface and control equipment of the endoscope robots shall be used repeatedly, and the manipulators used in the clean fields, are to be disposed of after each surgery".

\subsubsection{Mechanism of endoscope robot}

Fig. 5 shows the endoscope robot that we developed. System A of this robot is composed of a joystick interface and controller (control equipment). System B is composed of a disposable manipulator and general endoscopic device. The disposable parts are the manipulator, the tube and cylinder which send water to an actuator shown in Fig. 6. Since this endoscope robot was developed while System B was studied and developed, the joystick interface was used as a human machine interface so that System B could be easily evaluated and discussed. Human machine interfaces of this robot include automatic operation, voice recognition and a touch screen. Their explanation will be omitted.

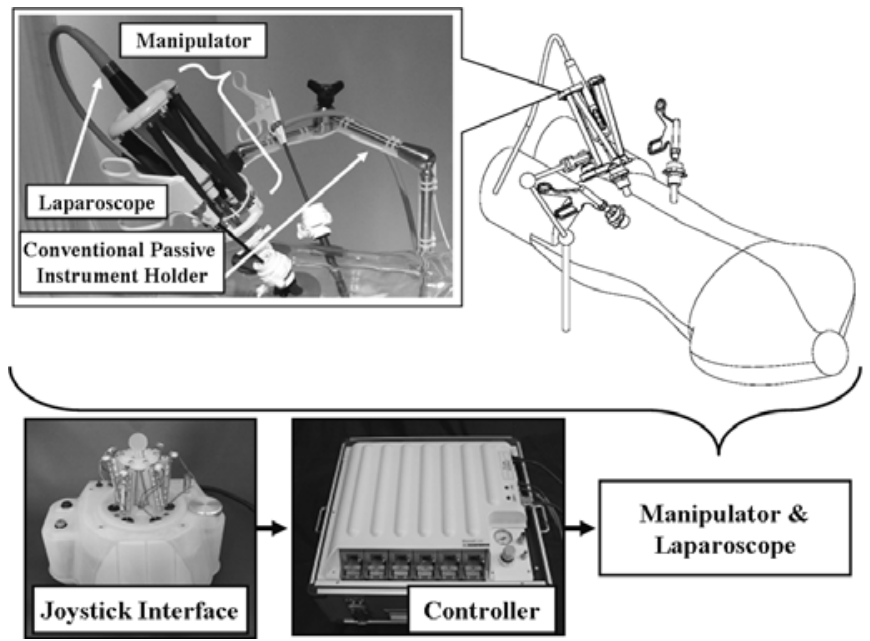

Fig. 5. System configuration

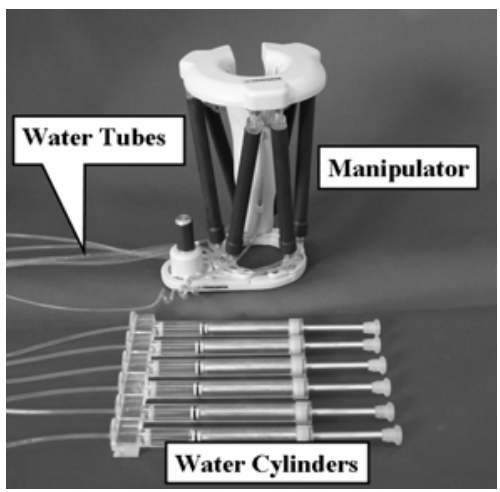

Fig. 6. Disposable part 
In our endoscope robot, the manipulator is composed of the Stewart-Gough Platform (six degrees of freedom parallel mechanism) (Tsai, 1999) and a linear actuator we developed and which can be sterilized is used for each element of the parallel mechanism. Our endoscope robot uses redundant six degrees of freedom. There have been some opinions that redundant degrees of freedom are unnecessary from the point of view of safety. This is because the runaway of a controller leads to unexpected movement of a manipulator since many of the endoscope robots developed so far use a serial mechanism or parallel linkage mechanism. Even if one of the actuators goes out of control, the parallel mechanism can suppress the runaway actuator with the other actuators; therefore, redundant degree of freedom will lead to safety. Hence, we selected six degrees of freedom of parallel mechanism focusing on safety. The parallel mechanism uses a smaller space with movement and can be more compact, trimmed weight and simplified, causing low cost compared to the serial mechanism when a tool (including an endoscope) operates in the narrow space such as in the human abdomen. Although high speed and accuracy are noticeable advantages in the parallel mechanism, we pay more attention to safety than high speed or high accuracy.

To enhance ease of installing the endoscope robot, we used a method where it can be installed to the surgical bed using a general abdominoscope holding arm which surgeons are familiar with, instead of using an installation table exclusively for endoscope robots. The advantages to this method are that medical staffs do not have to learn or have training on a new installation method and the endoscope robots can be easily installed or re-installed. Since the existing arm is used, development cost can be reduced, resulting in a competitive cost.

As a method for attaching the endoscope to the manipulator, we developed a way by using a permanent magnet. This method enables the endoscope to be installed during surgery and then, to possibly be removed during the same surgery, for cleaning the lens of the endoscope, resulting in securing the stability of the field of view (Fig.7).

We have developed a medical-use hydraulic disposable linear actuator for endoscope robots. Since this actuator can be sterilized and is disposable, it can be used in clean fields of surgery, without previous sterilizating. This actuator, supplying air of $0.4 \mathrm{MPa}$ from the tube to the actuator, applies force to a direction where an actuator is stretched continuously and the water is sent from the cylinder or pump installed outside of the clean field through the tube. Consequently the amount of the water pressure is controlled to shrink the actuator. It

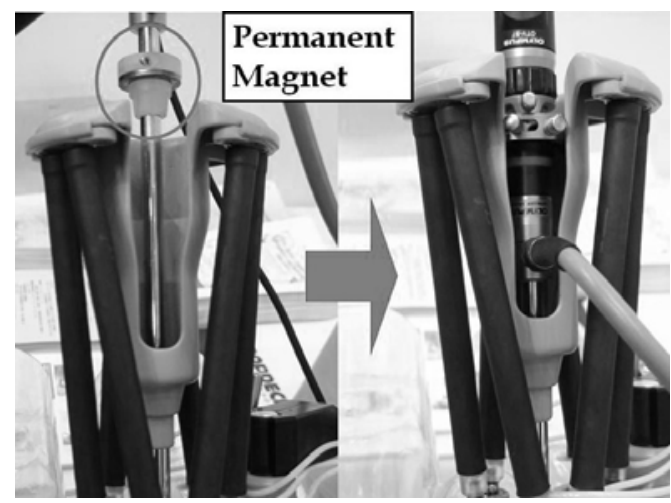

Fig. 7. Endoscope installation and removal mechanism using a permanent magnet 


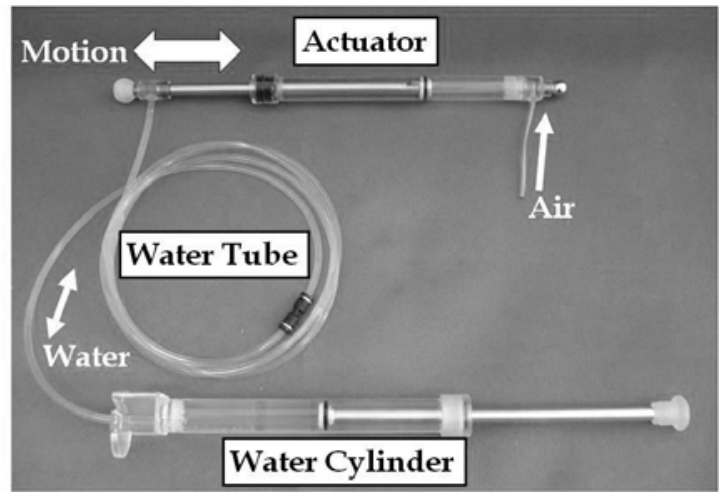

Fig. 8. Hydraulic linear actuator

is completely safe as there is no possibility of ground leakage in the clean field. This actuator measures $185.0 \mathrm{~mm}$ in length and $112.5 \mathrm{~mm}$ in amount of extension. This actuator maximally stretches when no control is applied to the cylinder (Fig. 8). When it is mounted in a robot, an endoscope is outstretched when no control or setting is performed (default) to the robot. Before surgery, a site for an endoscope is made on the patient's body, an endoscope is inserted into the site and the internal cavity is surveyed with the widest vision; therefore, providing a wide vision as a default can make settings easier and more efficient. Since force is applied to a direction where the endoscope is kept away from viscera, safety is improved.

As described above, the parallel mechanism is very safe. There is no chance of electrification and force is applied to a direction where an endoscope is kept away from the viscera all the time, resulting in extreme safety. As a method to improve the safety of an endoscope further, "shock absorber" and "up to three emergency stop switches" are added. The shock absorber, a permanent magnet spherical bearing is used for connection between the end plate of the manipulator and each actuator. This disconnects the actuators from the endplate and absorbs the shock when an endoscope interferes with organs or the manipulator contacts with a doctor (Fig.9). Since the endoscope robot has redundant six degrees of freedom, four degrees of freedom necessary for the endoscope operation is secured even though up to two actuators are dislocated. Actuators dislocated due to shock can be reinstalled at the original position with a single movement due to the permanent magnet spherical bearing. As independent and different systems, three emergency stop devices can be installed. We prepared two kinds of emergency stop devices. One of them is a pushbutton type installed near the joystick and is used when a camera assistant performs an emergency stop. The other one are foot pedals installed under the foot of the surgeon and assistant. Either of them could operate in case of emergency.

Each parameter of the manipulator is described below. These parameters are set for laparoscopic cholecystectomy.

- Dimension: Base plate radius: $48.5 \mathrm{~mm}$, end plate radius: $63.75 \mathrm{~mm}$, height when all actuators contract: $207 \mathrm{~mm}$

- Weight: About $580 \mathrm{~g}$ (The weight of endoscope and camera is not included.)

- Movement: Insertion/retraction: $112.5 \mathrm{~mm}$, movable maximum range: $26 \mathrm{deg}$

- Movement speed of actuators: $8 \mathrm{~mm} / \mathrm{sec}$ at a maximum 


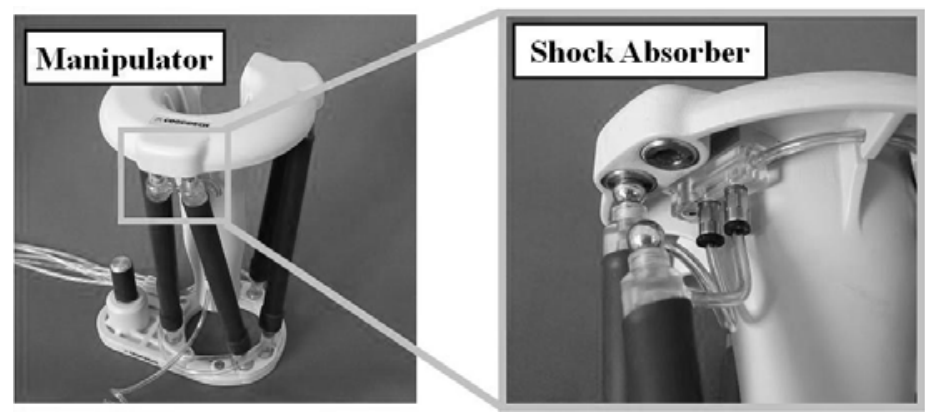

Fig. 9. Shock Absorber

\section{Evaluation methods of endoscope robots}

\subsection{Evaluation methods of endoscope robots}

Endoscope robots are evaluated using the information flow of LoopsAB and LoopsPB shown in Fig. 2. At the design stage, Loop SAB $_{\text {is evaluated and Loop }}$ is is mainly evaluated for test models. At this stage, the evaluation of each system in the LoopsAB is important and it is necessary to evaluate surgery results while facing up patients in the Loop model stages. For Loops ${ }_{\mathrm{SPB}}$ information quality, information density, the period when information is output, stability of the Loop, each element of the surgeons, patients and manipulators are evaluated. Information quality indicates the image quality taken by the endoscope, information density indicates the range of the field of view, and the period when the information is output means the surgery time. The state of the surgeons is evaluated by the psychological stress of the surgeons who use the robot. The state of the patients is evaluated by the degree of perfection of the surgery and the state of manipulators is evaluated by the amount of space occupied for movement and the operation experiments over a long period of time.

The followings are details of experiments of test models of endoscope robots with attention to information flow and their evaluation.

- in-vitro experiments using animals or human organs: Whether or not the range of the field of view of the endoscope robots (operation range) is sufficient is evaluated. Also, in order to check whether or not the manipulators will obstruct the movement of the surgeons during surgery, the amount of space used when the manipulators operate is evaluated. In addition, the psychological stress of the surgeons who use endoscope robots is evaluated. In this experiment, the evaluation standard is if endoscope robots can be used for laparoscopic cholecystectomy. Surgery time and degree of perfection of the surgery are also evaluated. Pig livers with cholecyst are mainly used in this experiment (amount, quality and period of information and each element).

- in-vivo experiment using animals: Details of the evaluation is the same as in in-vitro experiments where animals or human organs are used. In these experiment, fluctuation due to bleeding or breathing, particular to a living body, which cannot be evaluated in in-vitro experiment are evaluated (amount, quality and period of information and each element)

- Clinical test: Comprehensive evaluation is performed using endoscope robots for laparoscopic cholecystectomy of a human patient (amount, quality and period of information, each element). 
- Operation experiments over a long period of time: Durability of endoscope robots is evaluated. As an index time for the extensive operation experiment, we set the duration length, for three times the length of time that a manipulator is continuously used without maintenance (each element).

- $\quad$ Setup experiment: To evaluate if Loop ${ }_{\mathrm{SPB}}$ is easily constructed, the length of time for endoscope robot setup is evaluated. Whether medical staff who are using the endoscope robots for the first time can easily set up the robot without error is also evaluated (Loop stability)

- Endoscope lens cleaning experiment: Quality or stability of information in the LoopsPB depends on the cleanliness of the endoscope's lens. During in-vitro or in-vivo experiments, the time required for cleaning the endoscope lens and how easily the lens can be cleaned is evaluated. The index time for cleaning is $20 \mathrm{sec}$ (quality and stability of information)

- Correspondence experiment in emergencies: Assuming emergency situations such as an endoscope robot becoming out of control, the time required to switch from the surgery using the endoscope robot to surgery without the endoscope robot being used including halting and removal of the endoscope robot is evaluated (Loop stability).

- Evaluation of cleanliness of the endoscope robots: Quality of cleanliness is evaluated after cleaning or sterilization (each element)

For evaluation of Loop $\mathrm{SAB}_{\mathrm{B}}$, the strength of the endoscope robots, the operation range, the space required to operate the manipulators and the accuracy of movement with the human interface are evaluated during computer simulations at the design stages.

The details of each evaluation methods are described below.

\section{2 in-vitro experiment using pig livers with a cholecyst}

Laparoscopic cholecystectomy is normally used to evaluate endoscope robots [Yen et al., 2006, FDA, 2006]. This experiment frequently uses pig organs, not human organs. There are problems in ethical issues when human organs are used and pig organs have a relatively similar structure to human organs anatomically. This experiment simulates the environment by using a liver with a cholecyst to reproduce pseudo in-vivo environment and laparoscopic cholecystectomy where the cholecyst is removed from the liver. The experiment is performed in two cases where a camera assistant operates an endoscope and where a robot operates an endoscope and the results are compared. Livers equal to three times the number of experiments are prepared. Among the livers, the ones whose shapes and level of difficulty of surgery are similar are selected. The livers are placed in a surgery training box where an abdominal cavity is simulated to reproduce pseudo in-vivo environment. As examples, Fig. 10 shows an in-vitro experiment using a pig organ with P-arm as an endoscope robot and Fig. 11 shows an example of the device installation.

Next, specific details of evaluation are described.

- Whether images taken by an endoscope operated by a robot provides the same range of images as those taken by an endoscope operated by a camera assistant is evaluated. We aim at there being no difference in the images taken by endoscopes operated by robots and those operated by camera assistants. Surgeons evaluate whether there is no essential difference in a scale of enlargement of the image taken by endoscopes, the range of field of view and the angle of view for the surgery. Cholecystectomy is separated into three phases, bile duct treatment, cholecyst (body area) removal and treatment of the bottom of the cholecyst. Fig. 12 shows images taken by an endoscope in each phase during the experiment. 


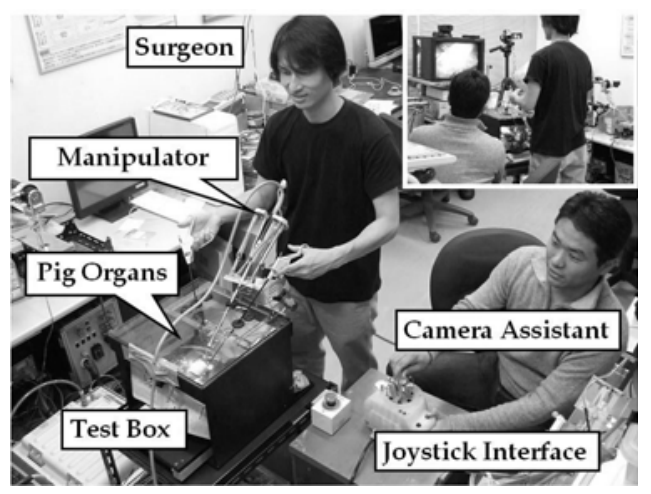

Fig. 10. in-vitro experiment

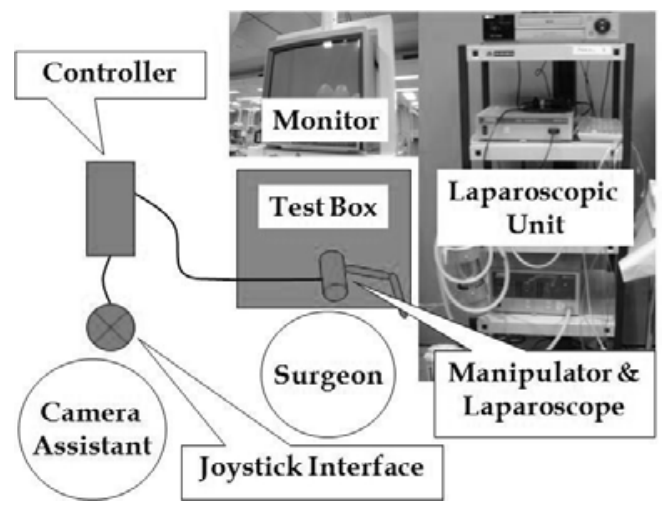

Fig. 11. Installation of devices in in-vitro experiment

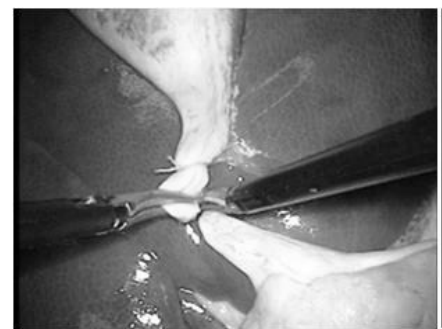

(a)

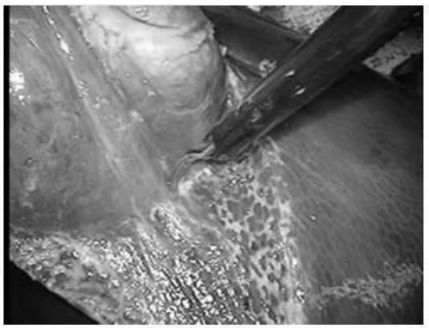

(b)

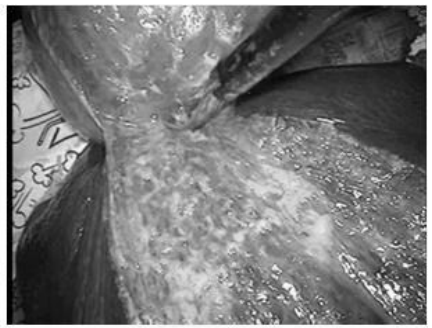

(c)

Fig. 12. Images taken by an endoscope during in-vitro experiment: a) Bile duct treatment, b) cholecyst (body area) removal, c) treatment of the bottom of the cholecyst

- Whether the space occupied by the manipulators obstructs the surgery or not is evaluated. Surgeons operate while they watch a monitor where the images are taken by an endoscope. If manipulators widely move and obstruct the hands of the surgeons, it is difficult for the surgeons to know the movement of the manipulators in advance. Manipulators and the hands of the surgeons are videoed during this experiment to 
make sure that there is no interference. After the experiment, we investigate whether the manipulators had interrupted the surgeons with questionnaires.

- Surgeons compare cases where the camera assistant operates the endoscope and where the robot operates the endoscope and evaluate whether the operation of an endoscope by the robot is not inferior to that of the camera assistant. Surgeons also evaluate the degree of perfection of the surgery.

- Surgeons' psychological stress during the experiment is measured when a camera assistant operates the endoscope and when a robot operates the endoscope. Whether surgeons have psychological stress or not by using an endoscope robot during surgery is objectively evaluated. The stress is measured using surgeons' salivary component and acceleration pulse wave. To evaluate whether surgeons are subjected to psychological stress due to the use of an endoscope robot during surgery, surgeons' saliva and acceleration pulse wave before and after surgery are measured. Then, they are analyzed and evaluated. Saliva cortisol and saliva a amylase are measured. The details are in a chapter of the In-Tech book"Advances in Human-Robot Interaction" (Taniguchi et al., 2009) for reference.

\section{3 in-vivo experiment using a pig}

Efficiency of endoscope robots are evaluated by performing a laparoscopic cholecystectomy on a pig based on problems including bleeding or fluctuation due to the patient's breathing, which is particular to living bodies. It is better to evaluate laparoscopic assisted distal gastrectomy and laparoscopic anterior resection as an advance surgery which needs a wide range of view. These procedures require a wide operation range and do not use endoscope robots since endoscope robots will interrupt surgery unless they are compact. As an example, Fig. 13 shows an in-vivo experiment where a pig is used and P-arm is used as an endoscope robot and Fig. 14 shows the installation location of devices. This laparoscopic cholecystectomy started when a trocar was placed on an anesthetized pig and cholecystectomy was performed and ended when the insertion site was sutured. The process during surgery was the insertion of an endoscope, adjustment of the range of view, movement of the field of view and removal of the cholecyst (gallbladder). Fig. 13 shows an in-vivo experiment with one surgeon and one camera assistant and a fixing supporting arm is used to hold the liver instead of a surgery assistant.

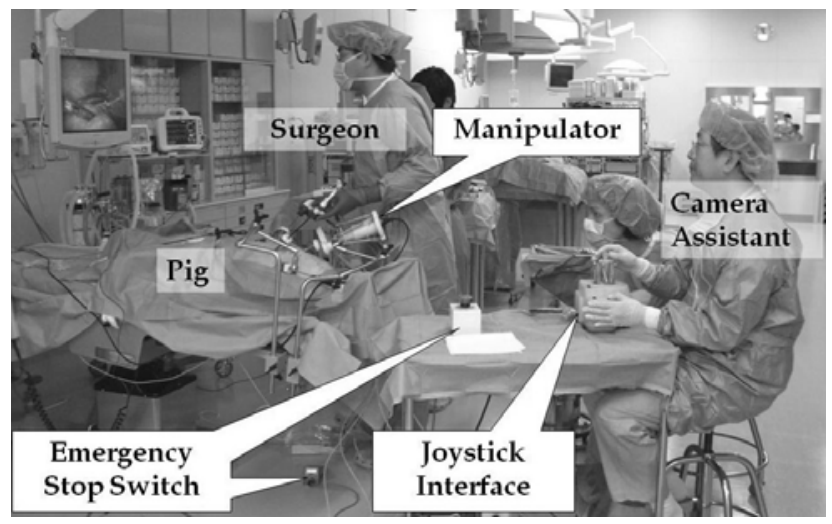

Fig. 13. in-vivo experiment 


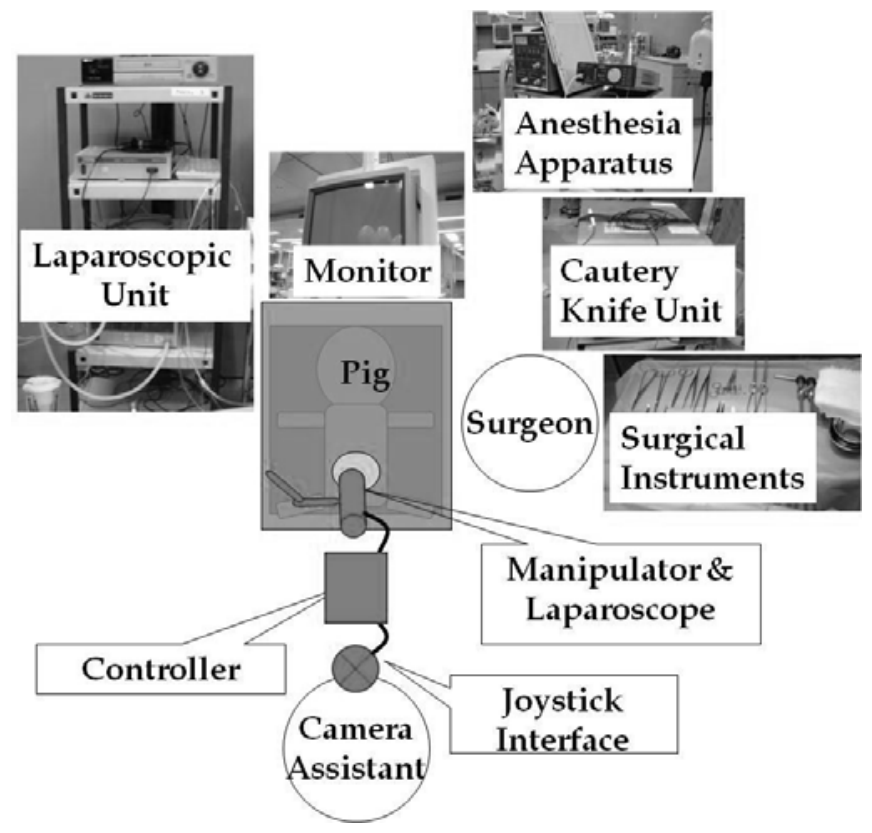

Fig. 14. Device installation for in-vivo experiment

Evaluation items for this experiment are the same in the in-vitro experiment using a pig liver with cholecyst described in section 4.2. The time for surgery to be measured is from when surgery started with the forceps inserted into the abdominal cavity to when the cholecyst is removed outside of the abdominal cavity (including robot setup time).

Fig. 15 shows images of bile duct treatment, cholecyst (body area) removal and removal of the bottom of cholecyst taken by an endoscope. Surgeons evaluate scale of enlargement, angle of field of view and range of view necessary for cholecystectomy.

Fig. 16 shows images of laparoscopic assisted distal gastrectomy taken by an endoscope. Fig.17 shows laparoscopic anterior resection. The number from 1 to 9 in Fig. 16 and 17 indicates progress of procedures.

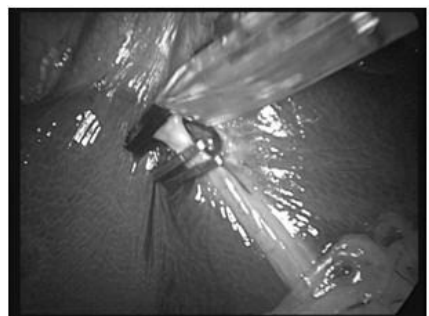

(a)

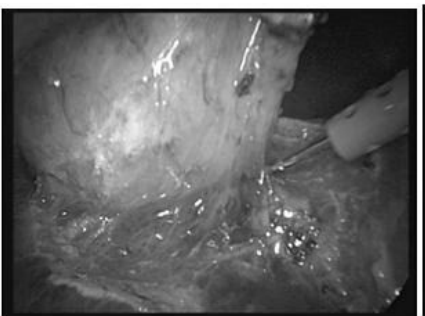

(b)

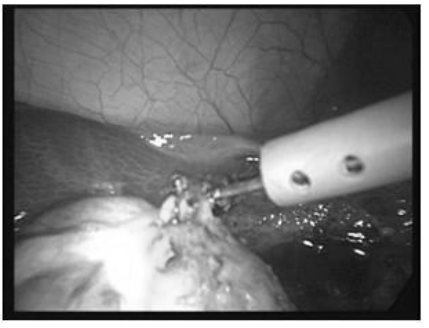

(c)

Fig. 15. Images taken by an endoscope during in-vivo experiment A)Laparoscopic image of the bile duct in an experiment, b)Laparoscopic image of the body of gallbladder in an experiment , c)Laparoscopic image of the fundus of gallbladder in an experiment 

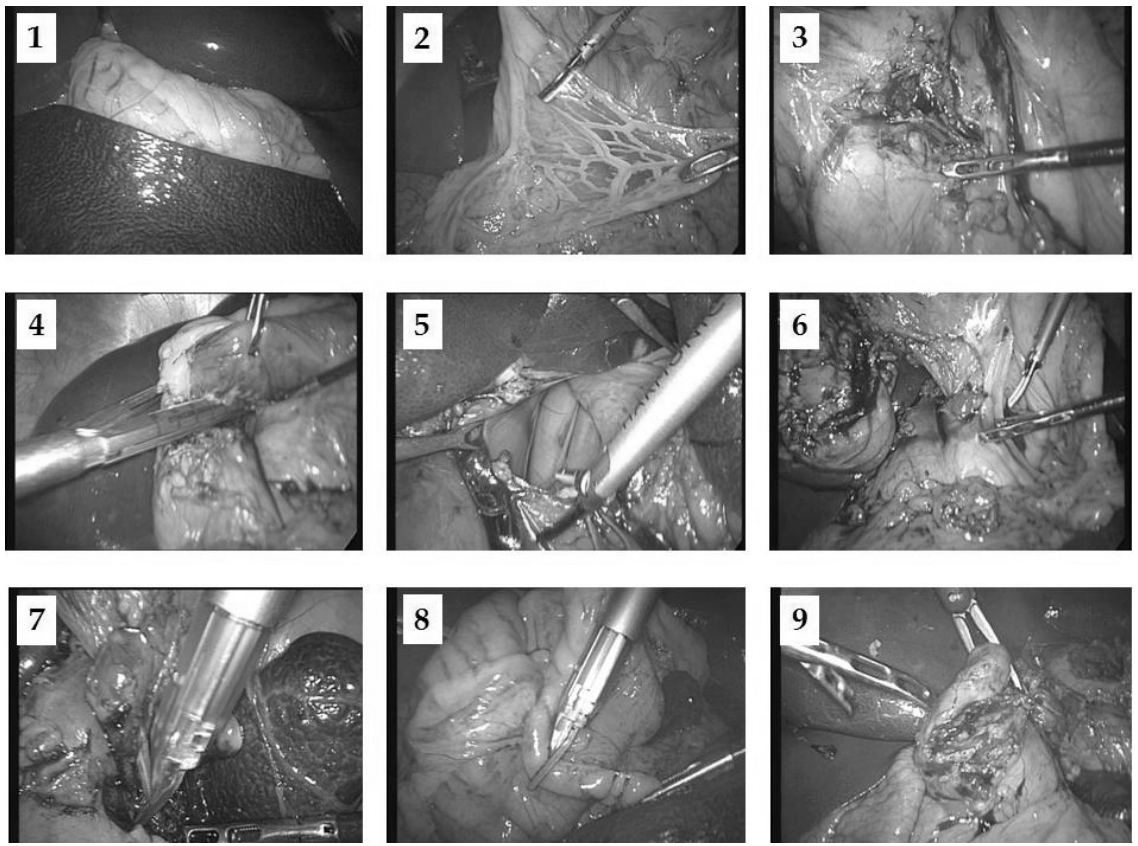

Fig. 16. Laparoscopic image of laparoscopic assisted distal gastrectomy (LADG)
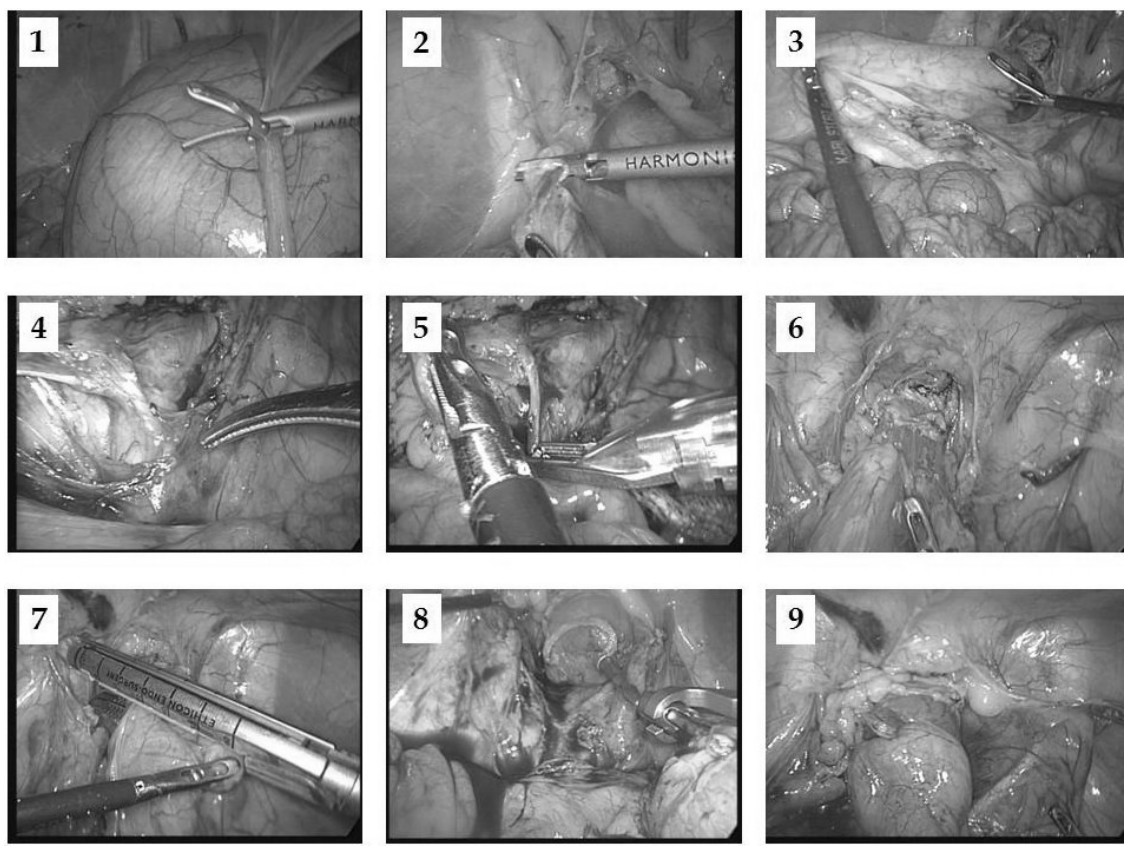

Fig. 17. Laparoscopic image of laparoscopic low anterior resection 


\subsection{Robot setting experiment, switching experiment from endoscope robot operation to manual operation assuming emergencies such as failure of a robot, endoscope lens cleaning experiment}

Details of evaluation items on Loop below.

- Robot setting experiment: The time it takes the surgeons to install the manipulator to the surgical table, the endoscope to the manipulator, and the endoscope to be positioned, is measured. This experiment is performed several times and the learning curve is analyzed and evaluated. It is desirable that the setup be easily performed in a short amount of time and that the time required for setting up should be shorter after the surgeons have become accustomed to the operation (LoopspB stability)

- Switching experiments from endoscope robot operation to manual operation: This experiment is performed to simulate handling when an emergency such as the failure of an endoscope robot occurs. The following time was measured; the endoscope robot was made to stop by pressing the emergency stop switch and the manipulator was moved, by the holding arm, to an area where the robot does not interrupt the surgery. Then, a normal surgery started where a human camera assistant positions the endoscope holding position. It is desirable that the above procedure is performed within $30 \mathrm{sec}$. (LoopspB stability)

- Endoscope lens cleaning experiment: The following time is evaluated; the endoscope is removed from the robot, the endoscope lens is cleaned, the endoscope is re-installed to the endoscope robot and the field of view is secured by the endoscope. The endoscope lens cleaning time when a human camera assistant operates the endoscope is about 20 sec. It is desirable that the lens cleaning time with the robot is also within $20 \mathrm{sec}$. (quality of information, Loop $\mathrm{SPB}$ stability)

\subsection{Operation experiment over a long period of time}

To discuss the durability of endoscope robots, continuous operation of the robot is performed for longer than three times that of an actual surgery. In this experiment, an endoscope, camera head and optical fibre cable are installed to an endoscope robot and the endoscope is inserted into the trocar which is installed to a human body model to simulate the usage environment of an actual surgery. For the robot movement, a control program

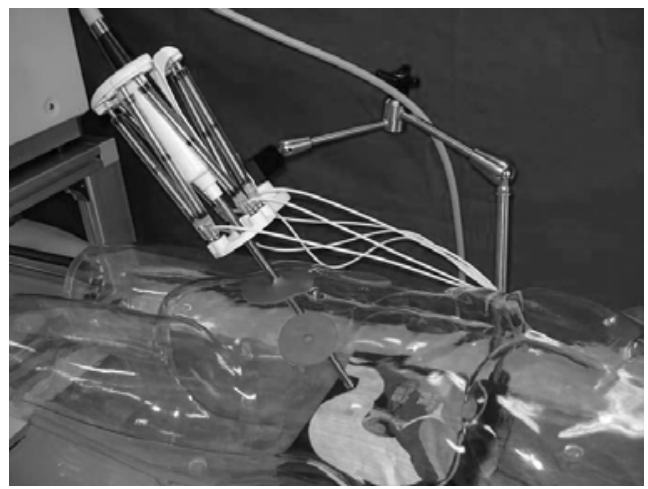

Fig. 18. Operation experiment over a long period of time 
developed for operation experiments over a long period of time moves four degree of freedom where speed and movable range is variously changed. Fig. 18 shows this experiment using P-arm as an example.

\subsection{Evaluation on cleanliness}

Sterilization methods include sterilization drape, gaseous sterilization, autoclave sterilization and electron-ray beam sterilization. When the sterilization drape is used, it is necessary to evaluate whether the sterilization drape does not tear due to the robot operation or the contact with medical staff. When gaseous sterilization, autoclave sterilization or electron-ray beam sterilization is used, specialized institutions evaluate and discuss cleanliness.

\subsection{Presenting at exhibitions}

Presentations of test models of endoscope robots at medical institute exhibitions should be made to gather opinions from others in the medical field, such as doctors, nurses or ME, It would also be advisable to make presentations of test models of endoscope robots at engineering exhibitions and to obtain opinions from the point of view of engineers.

\section{Development into the future}

Generally speaking, medical robotics is an academic framework of robots which provide "new eyes and hands" beyond the ability of human surgeons. Medical robots can be classified into treatment robots (surgical CAD/CAM systems), which perform surgery with image guidance and surgical assistant robots (surgical assistant systems), which assist in the treatment by the surgeons. Endoscope robots are classified into the surgical assistant robot [34]. This chapter treated endoscope robots as an interactive media and described the design and evaluation methods of endoscope robots. Our goal was to get a better understanding of endoscope robots while considering endoscope robots as interactive media, since endoscope robots closely interact with humans and assist with the surgery, coming in contact with patients around surgeons. Research and development of endoscope robots is striving for maintenance-free, compact, lightweight, automated, safe, clean and low cost endoscope robots; for the purpose of applying them to advanced surgeries. Diversion to NOTES of endoscope robots or single port surgery is not envisioned in the future. It is possible to make endoscope robots operate surgery devices such as forceps instead of endoscopes; however, easy diversion is a mistake. The reason is that methods to secure the required safety, accuracy or speed are totally different between the operation of an endoscope and the operation of forceps.

Development of endoscope robots has been well-established for the last 20 years and endoscope robots have been commercialized and active on the medical front. This chapter is written hoping that further study and development of endoscope robots spreads to all medical institutions where endoscopic surgery is performed and that endoscope robots will become partners with surgeons, for the benefit of many precious lives.

\section{Acknowledgement}

This research was supported in part by "Special Coordination Funds for Promoting Science and Technology: Yuragi Project" of the Ministry of Education, Culture, Sports, Science and 
Technology, Japan, Grant-in-aid for Scientific Research (A) (No. 19206047 ) of the Japan Society for the Promotion of Science.

\section{References}

Kobayashi, E.; Masamune, K.; Sakuma, I.; Dohi, T. \& Hashimoto, D. (1999). A New Safe Laparoscopic Manipulator System with a Five-Bar Linkage Mechanism and an Optical Zoom. Computer Aided Surgery, Vol.4, 182-192.

Tanoue, K.; Yasunaga, T.; Kobayashi, E.; Miyamoto, S.; Sakuma, I.; Dohi, T.; Konishi, K.; Yamaguchi, S.; Kinjo, N.; Takenaka, K.; Maehara Y. \& Hashizume, M. (2006). Laparoscopic cholecystectomy using a newly developed laparoscope manipulator for 10 patients with cholelithiasis. Surgical Endoscopy, Vol.20, No.5, 753-756, ISSN 0930-2794 (Print) 1432-2218 (Online).

Sackier, J. M. \& Wang, Y. (1994). Robotically assisted laparoscopic surgery form concept to development. Surgical Endoscopy, Vol.8, No.1, 63-66, ISSN 0930-2794 (Print) 14322218 (Online).

Finlay, P. A. (2001). A Robotic Camera Holder for Laparoscopy. Proceedings and Overviews of ICAR2001 Workshop 2 on Medical Robotics. Proceedings of the 10th International Conference on Advanced Robotics, 129-132. Aug. 2001, Budapest, Hungary

Nishikawa, A. ; Ito, K. ; Nakagoe, H. ; Taniguchi, K. ; Sekimoto, M.; Takiguchi, S. ; Seki, Y. ; Yasui, M. ; Okada, K. ; Monden, M. \& Miyazaki, F. (2006). Automatic Positioning of a Laparoscope by Preoperative Workspace Planning and Intraoperative 3D Instrument Tracking. MICCAI2006 Workshop proceedings, Workshop on Medical Robotics:Systems and Technology towards Open Architecture, 82-91.

Nishikawa, A.; Nakagoe, H.; Taniguchi, K.; Yamada, Y.; Sekimoto, M.; Takiguchi, S.; Monden, M. \& Miyazaki, F. (2008). How Does the Camera Assistant Decide the Zooming Ratio of Laparoscopic Images? -Analysis and Implementation-. Proceedings of the 11th International Conference on Medical Image Computing and Computer Assisted Intervention (MICCAI 2008) , New York, USA, Sep.2008.

Hurteau, R.; DeSantis, S.; Begin, E. \& Gagner, M. (1994). Laparoecopic Surgery Assisted by a Robotic Cameraman: Concept and Experimental Results. Proceedings of IEEE International Conference on Robotics \& Automation, 2286 - 2289.

Taylor, R. H.; Funda, J.; Eldridge, B.; Gomory, S.; Gruben, K.; LaRose, D.; Talamini, M.; Kavoussi, L. \& Anderson, J. (1995). A telerobotic assistant for laparoscopic surgery. IEEE Engineering in Medichine and Biology, vol.14. no.3, 279 - 288.

Munoz, V. F.; Vara - Thorbeck, C.; De Gabriel, J. G.; Lozano, J. F.; Sanchez-Badajoz, E.; Garcia-Cerezo, A.; Toscane, R. \& Jimenez-Garrido, A. (2000). A medical robotic assistant for minimally incasive surgery. Proceedings of IEEE International Conference on Robotics \& Automation, 2901 - 2906.

Munoz, V. F.; Gomez De Gabriel, J.; Garcia-Morales, I.; Fernandez-Lozano, J. \& Morales, J. (2005). Pivoting motion control for a laparoscopic assistant robot and human clinical trials. Advanced Robotics, vol.19, no.6, $694-712$.

Polet, R. \& Donnez, J. (2004). Gynecologic laparoscopic surgery with a palm-controlled laparoscope holder. The eburnal of the American Association of Gynecologic Laparoscopists, 73-78.

Mizhuno, H. (1995). Robotic Endo-Surgery System. Robot symposium 5th, 115 - 118 (in Japanese) 
Nishikawa, A.; Hosoi, T.; Koara, K.; Negoro, D.; Hikita, A.; Asano, S.; Kakutani, H.; Miyazaki, F.; Sekimoto, M.; Yasui, M.; Miyake, Y.; Takiguchi, S. \& Monden, Morito. (2003). FAce MOUSe: A Novel Human-Machine Interface for Controlling the Position of a Laparoscope. IEEE Transactions on Robotics and Automation, vol.19, no. $5,825-841$.

Funda, J.; Gruben, K.; Eldridge, B.; Gomory, S. \& Taylor R. H. (1995). Control and evaluation of a 7-axis surgical robot for laparoscopy. Proceedings of IEEE International Conference on Robotics \& Automation, 1477-1484.

EndoControl (2009). http:/ / www.endocontrol-medical.com/ [accessed October 10, 2009 ]

Long, J. A.; Cinquin, P.; Troccaz, J.; Voros, S.; Berkelman, P.; Descotes, J. L.; Letoublon, C. \& Rambeaud. J. J. (2007). Development of Miniaturized Light Endoscope-Holder Robot for Laparoscopic Surgery. eburnal of Endourology, vol.21, no8, 911-914.

Lee, Y. J.; Kim, J.; Ko, S. Y.; Lee, W. J. \& Kwon, D. S. (2003). Design of a Compact Laparoscopic Assistant Robot : KaLAR. Proceedings of the International Conference on Control Automation and Systems, 2648-2653.

Buess, G. F.; Arezzo, A.; Schurr, M .O.; Ulmer, F.; Fisher, H.; Gumb, L.; Testa, T. \& Nobman, C. (2000). A new remote-controlled endoscope positioning system for endoscopic solo surgery The FIPS Endoarm. Surgical Endoscopy, vol.14, 395 - 399.

Kimura, T.; Umehara, Y. \& Matsumoto, S. (2000). Laparoscopic cholecystectomy performed by a single surgeon using a visual field tracking camera. Surgical Endoscopy, vol.14 , $825-829$.

Kobayashi, E.; Sakuma, I.; Konishi, K.; Hashizume, M. \& Dohi, T. (2004). A robotic wideangle view endoscope using wedge prisms. Surgical Endoscopy, vol.18, 1396-1398.

Yamauchi, Y.; Yamashita, J.; Fukui, Y.; Yokoyama, K.; Sekiya, T.; Ito, E.; Kanai, M.; Fukuyo, T.; Hashimoto, D.; Iseki, H. \& Takakura K. (2002). A dual-view endoscope with image shift. Proceedings of CARS2002, 183 - 187.

Nakaguchi, T.; Makino H.; Igarashi T.; Kamimura K.; Tsumaru N. \& Miyake Y. (2005). An Automatic Tracking and Zooming System for Laparoscopic Surgery. Transactions of chpanese Society for Medical and Biological Engineeing, vol. 43, no. 4 685-693.

Taniguchi, K.; Nishikawa, A.; Yohda, T.; Sekimoto, M.; Yasui, M.; Takiguchi, S.; Seki, Y.; Monden, M. \& Miyazaki, F. (2006). COVER: Compact Oblique Viewing Endoscope Robot for laparoscopic surgery. Proceedings of CARS2006, 207.

Sekimoto, M.; Nishikawa, A.; Taniguchi, K.; Takiguchi, S.; Miyazaki, F.; Doki, Y. \& Mori, M. (2009). Development of a Compact Laparoscope Manipulator (P-arm). Surgical Endoscopy, ISSN0930-2794 (Print) 1432-2218 (Online)

Prosurgics (2009). http://www.freehandsurgeon.com/about.php [accessed October 10, 2009]

Sarkar, S.; Abolhassani, M. D.; Farahmand, F.; Ahmadian, A. R. \& Saber, R. (2009). Research Activities at the Research Centre for Science and Technology in Medicine, Iranian $J$ Publ Health, vol. 38, suppl. 1, 153-157.

Deshpande, S. (2004). http://www.lapindianrobot.com/robot1.htm [accessed October 10, 2009]

Szold, A.; Sholev, M.; Matter, I. (2008). Smart and slim laparoscopic robotic assistant. Proceedings of the 20th International Conference of Society for Medical Innovation and Technology (SMIT2008), 211. 
NGT, (2009). http://www.ngtnazareth.com/viewProject.asp?i=14 [accessed October 10, 2009]

Rininsland H. (1999). ARTEMIS: A telemanipulator for cardiac surgery. Europeaneburnal of Cardio-thoracic Surgery, vol.16, suppl. 2, 106-111.

KIT, (2009). http:// www.iai.fzk.de/www-extern/index.php?id=352\&L=1 [accessed October 10, 2009 ]

FZK, (2009). http://bibliothek.fzk.de/zb/Videolabor/hbm/Tabellen/Jahrg_00_fix.htm [accessed October 10, 2009]

Graur, F.; Plitea, N.; Vlad, L.; Pisla, D.; Vaida, C.; Furcea, L. \& Neagos, H. (2009). A Muresan, Experimental laparoscopic cholecystectomy using paramis parallel robot, Proceedings of the 21st International Conference of Society for Medical Innovation and Technology (SMIT2009).

Leveson, N. G. \& Turner, C. S. (1993). An Investigation of the Therac-25 Accidents. IEEE Computer, vol.26, no.7, 18-41.

Taylor, R. H. \& Stoianovici, D. (2003). Medical Robotics in Computer-Integrated Surgery IEEE Transactions on Robotics and Automation, vol. 19, no. 5, 765-781.

Tsai, L. W. (1999). Robot Analysis: The Mechanics of Serial and Parallel Manipulators. Wiley.

Yen, D.; Roxolana, H. \& Neil, O. (2006). US FDA regulation of computerized and robotics surgical systems. Proceedings of CARS2006.

FDA, (2006). http://www.jscas.org/guideline/FDA_CARS2006_Talk.pdf [accessed October 10, 2009]

Taniguchi, K.; Nishikawa, A.; Sugino, T.; Aoyagi, S.; Sekimoto, M.; Takiguchi, S.; Okada, K.; Monden, M. \& Miyazaki, F.(2009). Method for objectively evaluating psychological stress resulting when humans interact with robots. In-Tech book: Advances in Human-Robot Interaction, IN-TECH Education and Publishing. 


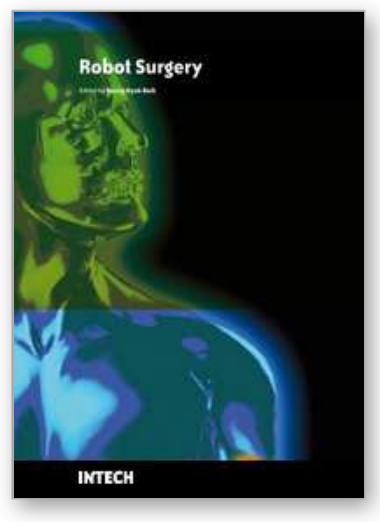

\author{
Robot Surgery \\ Edited by Seung Hyuk Baik
}

ISBN 978-953-7619-77-0

Hard cover, 172 pages

Publisher InTech

Published online 01, January, 2010

Published in print edition January, 2010

Robotic surgery is still in the early stages even though robotic assisted surgery is increasing continuously. Thus, exact and careful understanding of robotic surgery is necessary because chaos and confusion exist in the early phase of anything. Especially, the confusion may be increased because the robotic equipment, which is used in surgery, is different from the robotic equipment used in the automobile factory. The robots in the automobile factory just follow a program. However, the robot in surgery has to follow the surgeon's hand motions. I am convinced that this In-Tech Robotic Surgery book will play an essential role in giving some solutions to the chaos and confusion of robotic surgery. The In-Tech Surgery book contains 11 chapters and consists of two main sections. The first section explains general concepts and technological aspects of robotic surgery. The second section explains the details of surgery using a robot for each organ system. I hope that all surgeons who are interested in robotic surgery will find the proper knowledge in this book. Moreover, I hope the book will perform as a basic role to create future prospectives. Unfortunately, this book could not cover all areas of robotic assisted surgery such as robotic assisted gastrectomy and pancreaticoduodenectomy. I expect that future editions will cover many more areas of robotic assisted surgery and it can be facilitated by dedicated readers. Finally, I appreciate all authors who sacrificed their time and effort to write this book. I must thank my wife NaYoung for her support and also acknowledge MiSun Park's efforts in helping to complete the book.

\title{
How to reference
}

In order to correctly reference this scholarly work, feel free to copy and paste the following:

Kazuhiro Taniguchi, Atsushi Nishikawa, Mitsugu Sekimoto, Takeharu Kobayashi, Kouhei Kazuhara, Takaharu Ichihara, Naoto Kurashita, Shuji Takiguchi, Yuichiro Doki, Masaki Mori, and Fumio Miyazaki (2010). Classification, Design and Evaluation of Endoscope Robots, Robot Surgery, Seung Hyuk Baik (Ed.), ISBN: 978-953-7619-77-0, InTech, Available from: http://www.intechopen.com/books/robot-surgery/classificationdesign-and-evaluation-of-endoscope-robots

\section{INTECH}

open science | open minds

\section{InTech Europe}

University Campus STeP Ri

Slavka Krautzeka 83/A

51000 Rijeka, Croatia

\section{InTech China}

Unit 405, Office Block, Hotel Equatorial Shanghai

No.65, Yan An Road (West), Shanghai, 200040, China

中国上海市延安西路65号上海国际贵都大饭店办公楼405单元 
Phone: +385 (51) 770447

Fax: +385 (51) 686166

www.intechopen.com
Phone: +86-21-62489820

Fax: +86-21-62489821 
(C) 2010 The Author(s). Licensee IntechOpen. This chapter is distributed under the terms of the Creative Commons Attribution-NonCommercialShareAlike-3.0 License, which permits use, distribution and reproduction for non-commercial purposes, provided the original is properly cited and derivative works building on this content are distributed under the same license. 